\title{
Frontoethmoid Osteoma Causing Tension Pneumocephalus
}

\author{
Ahmet Celal Iplikcioglu Hamza Karabag ${ }^{2}$ \\ ${ }^{1}$ Department of Neurosurgery, Apex Cerrahi Tip Merkezi, i̇stanbul, \\ Turkey \\ ${ }^{2}$ Department of Neurosurgery, Harran Üniversity, Şanlıurfa, Turkey \\ J Neurosci Rural Pract 2019;10:548-550
}

Address for correspondence Hamza Karabag, Department of Neurosurgery, Harran Üniversity, Şanlıurfa 63300, Turkey (e-mail: hamzakarabag@yahoo.com).
Abstract
Keywords
- imaging
- osteoma
- paranasal sinus
- tension
pneumocephalus

Tension pneumocephalus is a life-threatening condition that is characterized by the accumulation of intracranial air, causing increased intracranial pressure. Paranasal sinus osteomas are common, slow-growing benign tumors usually diagnosed incidentally. Paranasal sinus osteomas causing tension pneumocephalus have been very rarely reported.

\section{Introduction}

Pneumocephalus is the presence of air or gas within the intracranial cavity. It is usually associated with head injury and surgical interventions including cranial, spinal, and paranasal sinus surgeries. Meningeal infections with gas-forming organisms, barotrauma, otitis media, paranasal sinus tumors, and nasopharyngeal carcinoma are rare causes of pneumocephalus. ${ }^{1}$

In most of the cases, intracranial air is scattered, and the amount of the air collected is less. However, if enough air gets collected within the intracranial cavity, increased intracranial pressure causing neurological deterioration occurs. This situation is called tension pneumocephalus that needs emergency surgical intervention.

In this report, we present a case of tension pneumocephalus due to frontoethmoidal sinus osteomas.

\section{Case Report}

A 24-year-old male was admitted to the hospital with the complaints of progressive headache for 1 week. A drowsiness also developed in the last 24 hours with several episodes of vomiting. There was no history of trauma, surgery, or rhinorrhea. His physical examination was normal.

Right hemiparesis and bilateral slight swelling of the optic discs were detected on neurological examination. Plain skull radiography revealed a right frontal air accumulation (-Fig. 1). Brain computed tomography (CT) scan showed frontoethmoid bony mass of $5 \mathrm{~cm}$ in diameter and a right frontal intracranial air collection ( - Figs. 2 and $\mathbf{3}$ ). There was

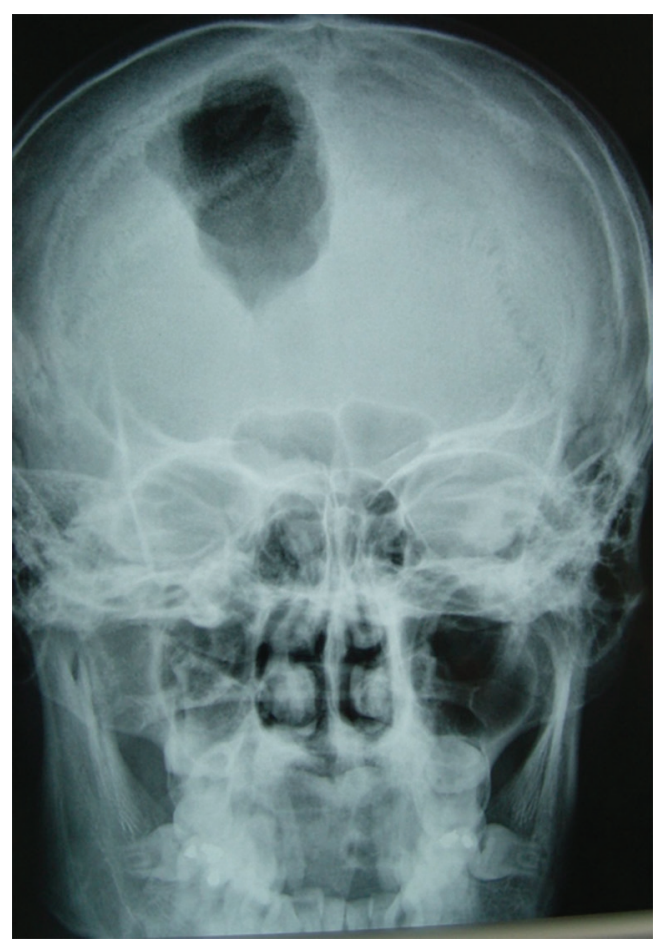

Fig. 1 Plain skull radiograph anteroposterior view reveals intracranial air collection. 
also an accompanying intraorbital air collection. The bony lesion was diagnosed as an osteoma. An emergency bifrontal craniotomy was performed. On surgery, the bony tumor and dural defect were seen. After the removal of air, and the tumor, the dural defect was repaired. Posterior wall of the frontal sinus was also reconstructed with a bony graft obtained from the internal tabula of bifrontal bone flab. The postoperative period was uneventful, and the patient was discharged without neurological deficits. Histopathological examination resulted in the diagnosis of osteoma.

\section{Discussion}

Osteomas of paranasal sinus are slow-growing and common benign tumors. ${ }^{2}$ They are usually diagnosed incidentally. Most of the paranasal sinus osteomas occur in the frontal and ethmoidal sinuses. They may grow within the sinus cavity and cause obstruction or infection with or without mucocele, presenting with fascial pain and headache. Intraorbital growth may also cause proptosis or diplopia more rarely. Intracranially growing osteomas may erode the sinus wall, dura, and arachnoid mater, resulting in cerebrospinal fluid (CSF) leakage, pneumocephalus, meningitis, or intracerebral

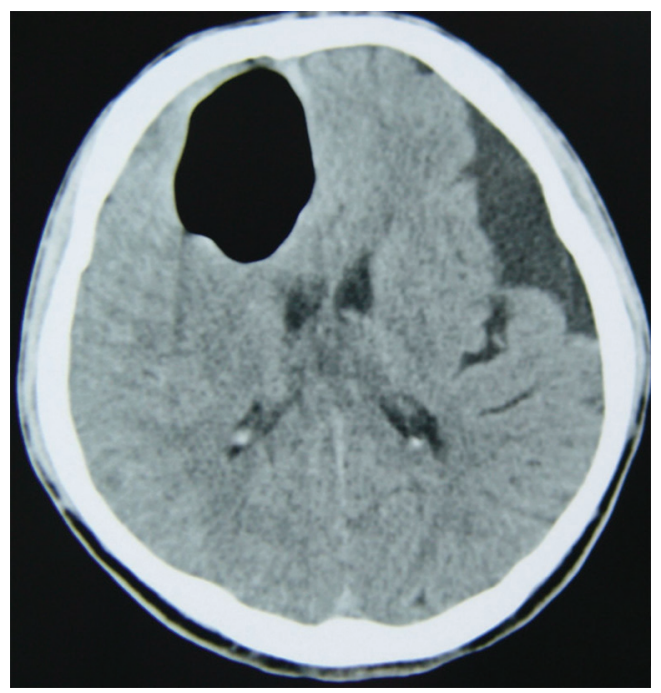

Fig. 2 Axial cranial computed tomography shows right frontal intracerebral air collection with midline shift. mucocele. However, unrecognized osteomas presenting with tension pneumocephalus have rarely been reported..$^{3-6}$

Dura mater of anterior cranial fossa is thin and close to the bone; therefore, meningeal perforation usually results in subdural air. Occasionally, dural adhesion to the brain tissue may also cause intracerebral air, whereas arachnoid dural adherence allows cisternal air. ${ }^{6}$

Two possible mechanisms of pneumocephalus associated with paranasal sinus osteomas are speculated as follows: ball valve mechanism and inverted bottle mechanism. In the ball valve mechanism, air is forced into the cranial cavity by sudden increase in nasopharyngeal pressure due to coughing, sneezing, or blowing nose. The valve prevents CSF and air outflow from the intracranial cavity. In the second theory, CSF flow creates a negative intracranial pressure and air enters into the intracranial cavity until the intracranial pressure balances with the air pressure. Presence of air in the intraorbital cavity has not been reported previously in similar cases; it suggests that the first mechanism is responsible for the development of pneumocephalus in our case.

Symptoms of pneumocephalus are related to the amount of air. Clinical symptoms are headache, nausea, vomiting, irritability, dizziness, and seizures. When tension pneumocephalus is present, frank neurological deficits such as hemiparesis, impairment of consciousness, and even cardiac arrest may develop in a few hours. However, patients with progressive symptoms over weeks or months had been reported. ${ }^{6}$

CT is the gold standard for the diagnosis of pneumocephalus. As low as $0.55 \mathrm{~mL}$ of air can be detected by CT. Osteomas can also be easily diagnosed on CT scan. Osteoma and air bubbles appear as low signal intensity on magnetic resonance imaging (MRI); hence, it is difficult to distinguish them consequently on MRI.

Tension pneumocephalus is a life-threatening condition and should be treated immediately. The goals of surgery are evacuation of the air repair, repair of the dural defect, and excision of the osteoma.

\section{Conclusion}

Although osteomas of paranasal sinus are benign lesions, they may cause life-threatening intracranial complications,
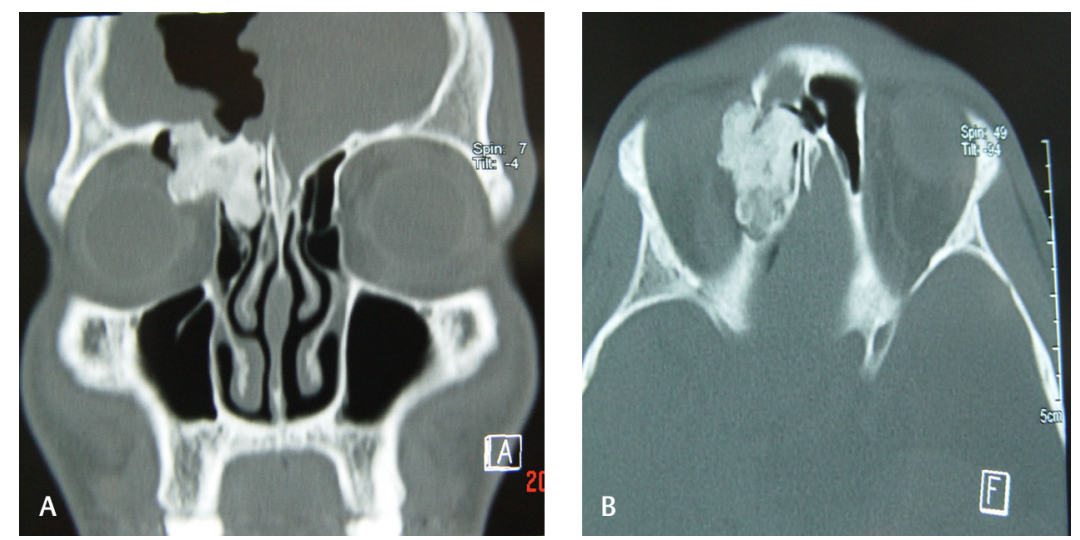

Fig. 3 Coronal (A) and axial (B) bone window computed tomography of paranasal sinus demonstrating lobulated osseous lesion within the right frontal sinus associated with intracranial air collection. 
such as tension pneumocephalus. Patients with paranasal sinus osteomas should be followed up closely by imaging. When tension pneumocephalus occurs, emergency surgical intervention is needed.

\section{Funding}

None.

\section{Conflict of Interest}

None declared.

\section{References}

1 Choi YY, Hyun DK, Park HC, Park CO. Pneumocephalus in the absence of craniofacial skull base fracture. J Trauma 2009;66(2):E24-E27
2 Cheng KJ, Wang SQ Lin L. Giant osteomas of the ethmoid and frontal sinuses: clinical characteristics and review of the literature. Oncol Lett 2013;5(5):1724-1730

3 Johnson D, Tan L. Intraparenchymal tension pneumatocele complicating frontal sinus osteoma: case report. Neurosurgery 2002;50(4):878-879, discussion 880

4 Kamide T, Nakada M, Hayashi Y, Hayashi Y, Uchiyama N, Hamada J. Intraparenchymal pneumocephalus caused by ethmoid sinus osteoma. J Clin Neurosci 2009;16(11):1487-1489

5 Kendre B, Deopujari C, Karmarkar V, Shah S. Frontal sinus osteoma with pneumocephalus and progressive hemiparesis. Neurol India 2013;61(6):694-695

6 Onal B, Kaymaz M, Araç M, Doğulu F. Frontal sinus osteoma associated with pneumocephalus. Diagn Interv Radiol 2006;12(4):174-176 